\title{
ANALISIS MANAJEMEN LEMBAGA BAHASA ARAB DALAM MENINGKATKAN KUALITAS PEMBELAJARAN
}

\author{
1. Isman Iskandar, ${ }^{2}$ Sri Widyastri, \\ ${ }^{1 .}$ IIQ Jakarta, ${ }^{2 .}$ UIN Jakarta, \\ 1. isman@iiq.ac.id ${ }^{2 .}$ sri_widyastri19@mhs.uinjkt.ac.id
}

\begin{abstract}
This paper tries to reveal and elaborate the management of the Tebet Al-Risalah Institute, South Jakarta. The Al-Risalah Institute is an institution engaged in Arabic language education and special training for Indonesian citizens. An educator who is a specialist in teaching Arabic from Sudan who has 15 years of experience in Indonesia. Although there have been many non-formal institutions that have organized courses and training that are growing rapidly in Indonesia, they have experienced a drastic decline in the effectiveness and efficiency of institutional management. Al-Risalah is present in the midst of Indonesian society who provides quality assurance in terms of institutional management and learning. This study uses a qualitative approach that describes critically the discovery of meaning. The type and strategy used in this research is case study research by analyzing educational management theory. Data collection techniques are interviews, observation and documentation. The results showed that the Al-Risalah planning had a program; training, intensive Arabic, online Arabic, professional Arabic and the I'dad Lughawi program with the target of learning to have 4 language proficiency: listening, reading, speaking and writing skills. The organizational management aspect was found to be still weak due to several obstacles such as: concurrent staff, unclear organizational structure because the leader only gave tasks verbally to subordinates, but Al-Risalah prioritized the aspects of communication and deliberation together between leaders, heads of departments and staff. In the implementation aspect, the leadership of AlRisalah motivates, provides motivation so that they can carry out their duties with discipline, effectiveness and optimism. Evaluation aspect, Al-Risalah monitors and controls the discipline of teachers, course participants and staff both structured and unstructured.
\end{abstract}

Keywords: Management, Educational Institutions, Arabic

\begin{abstract}
ABSTRAK
Tulisan ini mencoba mengungkap dan mengelaborasikan manajemen Lembaga AlRisalah Tebet, Jakarta Selatan. Lembaga Al-Risalah adalah lembaga yang bergerak di bidang pendidikan bahasa Arab dan Pelatihan khusus warga Indonesia. Pendidik yang merupakan tenaga ahli spesial pengajaran bahasa Arab dari Sudan yang sudah berpengalaman selam 15 tahun di Indonesia. Meskipun sudah banyak lembaga nonformal yang menyelenggarakan kursus dan pelatihan yang berkembang pesat di Indonesia, namun mengalami penurunan drastis dari aspek efektivitas dan efisiensi manajemen kelembagaan. Al-Risalah hadir di tengah-tengah masyarakat Indonesia yang memberikan jaminan kualitas dalam hal manajemen kelembagaan dan pembelajaran. Penelitian ini menggunakan pendekatan kualitatif yang mendeskripsikan secara kritis dalam penemuan makna. Tipe dan strategi yang digunakan dalam penelitian ini yaitu case study research
\end{abstract}


dengan menganalisis teori manajemen pendidikan, Teknik pengumpulan data yaitu interview, observasi dan dokumentasi. Hasil penelitian menunjukkan bahwa perencanaan Al-Risalah memiliki program; training, bahasa Arab intensif, bahasa Arab Online, bahasa Arab Profesi dan Program I'dad Lughawi dengan target pembelajaran memiliki 4 kemahiran berbahasa: keterampilan mendengar, membaca, berbicara, dan menulis. Aspek manajemen pengorganisasian ditemukan masih lemah karena beberapa kendala seperti: staf yang merangkap, struktur organisasi yang belum jelas karena pemimpin hanya memberikan tugas secara lisan kepada bawahan namun Al-Risalah mengedepankan aspek komunikasi dan musyawarah secara bersama-sama antar pimpinan, kepala bagian dan staf. Aspek pelaksanaan, pimpinan Al-Risalah menggerakkan, memberikan motivasi agar dapat dengan penuh kesadaran melaksanan tugas dengan disiplin, efektif dan optimal. Aspek pengevaluasian, Al-Risalah menonitoring dan mengontrol disiplin pengajar, peserta kursus dan staf baik dengan terstrutktur dan tidak terstruktur.

Kata Kunci: Manajemen, Lembaga Pendidikan, Bahasa Arab.

\section{PENDAHULUAN}

Era digital saat ini menjadi tuntutan sekaligus tantangan bagi lembaga-lembaga pendidikan Islam agar terus inovatif dan kreatif. Terutama pada lembaga pendidikan bahasa yang kini kian diminati sebagai connector antara peserta didik dengan dunia global. Manajemen lembaga menjadi hal yang utama dan pertama untuk mengupgrade mutu dan kualitas sebagai penopang connector tersebut. Lembaga pendidikan Islam adalah lembaga atau tempat berlangsungnya proses pendidikan yang dilakukan dengan tujuan untuk mengubah tingkah laku individu ke arah yang lebih baik melalui interaksi dengan lingkungan sekitarnya. Perubahan dimaksud tentunya dilandasi oleh nilai-nilai Islami. (Kholili \& Fajaruddin, 2020, hal. 12).

Upaya dan usaha global maupun nasional yang berfokus kepada pengembangan kualitas lembaga pendidikan baik itu mengadakan konferensi dan seminar serta membentuk komite khusus agar dapat mengukur kualitas lembaga-lembaga pendidikan. (Msallam et al., 2020, hal. 73). Kemajuan sains tersebut harus diiringi dengan peningkatan manajemen yang baik agar lembaga-lembaga pendidikan Islam bermutu dan mampu berkompetitif di era modern ini. Dengan berbagai muatan dan modifikasinya, lembaga-lembaga tersebut menjadi institusi andalan umat Islam dalam proses pembelajaran dan pendidikan Islam. (Widyastri \& Iskandar, 2020, hal. 20) .

Beberapa kajian ilmiah yang menunjukkan bahwa implementasi manajemen dapat meningkatkan mutu lembaga. Implementasi manajemen strategik yang dilakukan 
oleh SMP Muhammadiyah Al-Mujahidin dan SMP Muhammadiyah Semin melibatkan semua stakeholder. Sekolah terlebih dahulu merumuskan visi misi sekolah dengan mempertimbangkan faktor internal dan eksternal lingkungan sekolah, dilanjutkan merumuskan tujuan dan target mutu sekolah diikuti dengan penentuan strategi yang akan digunakan oleh sekolah demi terealisasikannya semua target mutu yang disepakati. (Kholili \& Fajaruddin, 2020, hal. 53). Peningkatan mutu pendidikan yang ada di Darul Qur'an Semarang berjalan dengan baik dan selalu terjaga mutu disebabkan dengan pengimplementasian audit internal, namun terkadang pelaksanaan kegiatan perencanaan seringkali tidak sesuai dengan harapan. (Andi, 2020, p. 336).

Hal yang sama didapati dari penelitian Isman Iskandar bahwa Ma'had Salafiyah di Kabupaten Sidrap memiliki manajemen perencanaan perhari hingga perminggu, pengorganisasian termasuk kategori terbuka dan mempersilahkan siapa pun bisa ikut andil, pelaksanaan dakwahnya terlaksana dengan baik dan Istiqamah meski sumber daya terbatas dan pengawasannya berdasarkan pelaksanaan kegiatan berdasarkan dalil dan petunjuk Nabi SAW. (Iskandar et al., 2017, hal. 44)

Manajemen juga dibutuhkan dalam merancang proses pembelajaran yang efektif dan efisien. Munculnya berbagai aplikasi Learning Management System (LMS) mendukung terlaksananya pembelajaran bahasa Arab dengan model blended learning yang memadukan metode tradisional (tatap muka) dan online. (Taufiqurrochman et al., 2020, hal. 2) Selanjutnya, perencanaan, implementasi dan evaluasi dalam manajemen pembelajaran di IAIN Pare-pare dapat meningkatkan prestasi belajar, kemampuan berpikir kritis dan kreatif. (Sewang \& Halik, 2020, hal. 2732).

Manajemen diartikan sebagai penggunaan sumber daya secara efektif untuk mencapai sasaran. (KBBI, 1986: 716). Manajemen berasal dari kata to manage yang artinya mengatur. Lebih lanjut, Hasibuan menjelaskan bahwa pengaturan yang dilakukan melalui proses serta diatur berdasarkan urutan dari fungsi-fungsi manajemen. (Malayu Hasibuan, 2007: 1). Manajemen berusaha mengatur agar sumber daya dikelola secara efektif dan efisien untuk mendapatkan tujuan yang ditetapkan. (Sri Widyastri, 2020: 21).

Sedangkan secara terminologi terdapat banyak definisi oleh para ahli, di antaranya adalah Robert Kreitner memaknai manajemen dalam bukunya sebagai berikut: Management is a the procces of working with and through other to achieve organizational objectives in a changing environment. Central to this process is the 
effective and efficient use of limited resources. (Robert Kreitner, 1989: 9). Dalam bahasa Arab, istilah manajemen diartikan al-niz\}a>m dan al-tanz\}im yang merupakan suatu tempat untuk menyimpan segala sesuatu dan penempatan segala sesuatu pada tempatnya. (Ahmad Warson Munawwir, 1997: 1435). Dari beberapa definisi di atas, penulis menyimpulkan bahwa manajemen dalam arti yang lebih luas yaitu suatu pengaturan sistematis dan terukur yang membuat semua orang terikat dengan prinsip-prinsip dalam budaya organisasi serta orang-orang mampu merealisasikannya dan merasa bertanggung jawab.

Hal yang sama dikemukakan juga oleh Abdalqader A Msallam bahwa yang membedakan suatu negara maju yaitu ketika mereka menerapkan konsep manajemen tersebut dalam lembaga pendidikan, serta nilai dan prinsip manajemen membuat semua orang di organisasi mengetahui bahwa kualitas merupakan tanggung jawabnya. (Msallam et al., 2020, hal. 21). Pada intinya manajemen berusaha mengatur sumber daya secara efektif untuk mencapai tujuan yang ditetapkan. (Iskandar et al., 2017, hal. 48). Manajemen merupakan suatu seni dalam ilmu dan pengorganisasian seperti menyusun perencanaan, membangun organisasi dan pengorganisasiannya, pergerakan, serta pengendalian atau pengawasan. (Kholili \& Fajaruddin, 2020, hal. 6) Dalam definisi luas, pada umumnya di bidang pendidikan, pemerintah dan kemiliteran orang memakai istilah administrasi, sedangkan di bidang industri dan perusahan dipakai istilah manajemen.(Wijaya, 2020, hal. 56).

Penentuan segala sesuatunya terlebih dahulu, untuk melaksanakan sebagai kegiatan dan aktivitas, itulah yang disebut dengan istilah "planning". planning adalah penentuan terlebih dahulu apa yang akan di kerjakan. Penentuan ini juga merencanakan tindakan secara efektif dan efisien dan mempersiapkan input dan output.

Pengorganisasian (organizing)

Pengorganisasian adalah proses yang menyangkut bagaimana strategi dan taktik yang telah dirumuskan dalam perencanaan didesain dalam sebuah struktur organisasi yang tepat dan tangguh, sistem dan lingkungan organisasi yang kondusif, dan bisa memastikan bahwa semua pihak dalam organisasi bisa bekerja secara efektif dan efisien guna pencapaian tujuan 
Pelaksanaan (actuating)

Adapun istilah yang dapat dikelompokkan ke dalam fungsi actuating ini adalah directing, commanding, leading, dan koordinating. Pelaksanaan adalah menerapkan program agar bisa dijalankan oleh seluruh pihak dalam organisasi serta proses memotivasi agar semua pihak tersebut dapat menjalankan tanggung jawabnya dengan penuh kesadaran dan produktivitas yang tinggi.

Pengendalian (pengawasan) atau controling

Pengendalian (pengawasan) atau controling adalah bagian terakhir dari fungsi manajemen. Fungsi manajemen yang dikendalikan adalah perencanaan, pengorganisasian, pengarahan, dan pengendalian itu sendiri. (Husaini Usman, 2010, p 503).

Salah satu lembaga yang menerapkan sistem manajemen kelembagaan adalah AlRisalah. Penerapan sistem manajemen ini tidak terlepas dari sejarah pendiri al-Risalah yaitu Ali Hussein Morgan yang pernah belajar di University of Madras Chennai juga memiliki beberapa perusahaan dibidang ekspor-import barang dari Timur Tengah. Sehingga motivasi manajemen yang diimplementasikan di Al-Risalah tidak terlepas dari manajemen pemimpin yang terpatri dalam diri Ali Hussein Morgan.

Hal yang menarik dari Al-Risalah yaitu upaya menjadikan bahasa Arab sebagai bahasa yang paling diminati oleh masyarakat Muslim Indonesia. Al-Risalah memiliki pembelajaran eksklusif dan kualitas para pengajar lansung dari Timur Tengah khususnya negara Sudan yang sudah bergelar Doktor. Program Al-Risalah yaitu: Program Bahasa Arab intensif, online, profesi, kuliah umum dan seminar, training, i'dad Lughawi, danprogram weekend. Program-program tersebut mendapatkan perhatian positif yang sangat cukup tinggi dari masyarakat. Hal ini dapat dilihat dari tingginya antusias masyarakat baik kalangan siswa, mahasiswa, dosen bahkan ibu rumah tangga yang mendaftarkan dirinya untuk mengikuti sistem pembelajaran tersebut. Dari latar belakang tersebut, penulis tertarik untuk mengkaji lebih luas bagaimana manajemen lembaga Al-Risalah dalam meningkatkan kualitas pembelajaran siswa.

\section{METODE PENELITIAN}

Penelitian ini mencoba untuk melihat manajemen lembaga Al-Risalah dan peran manajemen tersebut dalam meningkatkan kemampuan berbahasa santri Al-Risalah. Jenis 
penelitian ini adalah kualitatif-deskriptif kemudian menggunakan teori manajemen. Obyek penelitian dilakukan di lembaga Al-Risalah yang berlokasi di Wisma Alena, Tebet, Jakarta Selatan. Melalui pengamatan peneliti di lapangan dengan menghimpun data-data obyektif. Alasan memilih tempat ini karena pertimbangan historis dan pengalaman peneliti sebagai santri di lembaga Al-Risalah. Sumber data penelitian ini dibagi menjadi dua macam, yaitu: sumber data primer dan sekunder. Sumber data primer dalam penelitian adalah data yang belum dipublikasikan dan kemudian peneliti dapat mengumpulkannya secara langsung dari orang atau lembaga, yaitu 1 orang pimpinan, 3 orang ustad dan 4 orang santri serta 3 orang staf. Sumber primer ini adalah data wawancara kerja lapangan dan data dokumen yang belum dipublikasikan. Sumber data sekunder yang digunakan dalam penelitian ini berupa publikasi jurnal, hasil penelitian kitab ajar, kurikulum dan catatan yang dipublikasikan.

Instrumen pengumpulan data melalui wawancara, observasi dan dokumentasi. Sedangkan teknik analisis data yaitu reduksi data, display data dan kesimpulan. Pembahasan data akan menggunakan analisis SWOT (strength, weakness, opportunities dan treaty). (Sutojo, 2002: 22).

\section{HASIL DAN PEMBAHASAN}

Realitas Lembaga Al-Risalah Pendidikan Bahasa Arab dan Pelatihan

Al-Risalah adala lembaga pelopor dalam bidang penelitian, konsultasi dan pelatihan, spesialisasi dalam pengajaran bahasa Arab. Untuk penutur Non-Arab, Studi Islam, sumber daya manusia dan ekonomi Islam. Al-Risalah hadir di tengahtengah masyarakat Indonesia untuk memberikan kemudahan bagi siapa saja yang ingin belajar bahasa Al-Qur'an. Sehingga melalui lembaga ini bahasa Arab mampu disebarkan dan diajarkan kepada semua kalangan masyarakat Indonesiayang mencintai bahasa Arab. Juga masyarat Indonesia berusaha untuk mempelajarinya dengan bersungguh-sungguh.

Sebagai acuan dalam menjalani kegiatan setiap hari, kemajuan dan perkembang pesat serta eksistensi Al-Risalah tentu tidak bisa terlepas dari Visi dan Misi. Pentingnya visi dan misi dalam sebuah lembaga sebagai haluan dalm menentukan arah dan pencapain tujuan serta bagaimana dan apa saja yang dilakukan sebuah lembaga guna mewujudkan cita-citanya. Selanjutnya akan diuraikan tentang visi dan 
misi Al-Risalah. Visi Ar-Risalah yaitu menjadikan lembaga pendidikan bahasa Arab dan pelatihan yang terdepan dalam mewujudkan generasi Islam yang berilmu dan berprinsip pada Al-Qur'an serta menjadikan lembaga pendidikan bahasa Arab dan pelatihan paling banyak diminati oleh berbagai kalangan tanpa batasan usia dan menjadi salah satu lembaga terkemuka di Indonesia.

Adapun misi Al-Risalah adalah: pertama, menyelenggarakan pembelajaran bahasa Arab tanpa batasan usia, waktu dan jarak, kedua, memperkenalkan bahasa Arab ke masyarakat Indonesia untuk terwujudnya pendidikan bahasa Arab yang unggul, ketiga, memberikan pembelajaran yang merujuk ke Al-Qur'an, keempat, memberikan suasana belajar seperti di Negara Timur Tengah tanpa batasan usia. Kelima, menyelenggarakan kerjasama dengan berbagai instansi, universitas, lembaga, yayasan, sekolah dan lain-lain di Indonesia dalam bentuk training guru dan pelajar.

Setiap lembaga pasti memiliki distingsi atau keistimewaan yang menjadi daya tarik lembaga tersebut. Hal ini pun tidak luput dari lembaga Al-Risalah yang memiliki komitmen untuk mengajarkan bahasa Arab untuk masyarakat Indonesia. Keunggulan tersebut yaitu: pertama, dapat berbahasa Arab dalam waktu satu tahun (terdapat delapan level dan setiap level dapat diselesaikan dalam kurang waktu satu setengah bulan). Kedua, menggunakan strategi belajar bahasa Arab yang mencakup 4 kecakapan berbahasa, yaitu: mendengar (istima'), berbicara (kalam), membaca (qira'ah) dan menulis (kitabah) yang menjadikan pembelajaran menjadi mudah, menyenangkan, cepat dan mandiri. Ketiga, diajarkan oleh dosen Ahli spesial pengajaran bahasa Arab untuk non Arab dari Sudan Timur Tengah. Keempat, menyediakan kelas bahasa Arab online. Keempat, menyediakan kurikulum pembelajaran bahasa Arab yang mudah dimengerti dan dipahami oleh berbagai kalangan tanpa batasan usia. Kelima, membuka kelas i'dad lughawi atau kelas persiapan bahasa Arab dan budaya bagi para pelajar yang ingin melanjutkan studi di negara-negara Timur Tengah.

\section{Struktur Organisasi}

Secara makro, Al-Risalah sebaga lembaga pendidikan dan bahasa Arab memiliki dewan penasehat. Dewan penasehat Al-Risalah yaitu: Hassan Mohammad Doka (Tokyo-Japan), Salah Madani Mohammed (Tokyo-Japan) dan Yassin Mohamed Yassin (Los Angeles-USA). Ketiga dewan penasehat tersebut bertujuan untuk 
memberikan saran dan pendapat kepada Al-Risalah dalam hal teknis pembelajaran. Hal yang menarik adalah dewan penasehat tersebut adalah orang Sudan yang telah bekerja di Jepang dan di Amerika sekaligus mengajarkan bahasa Arab. Kemudian, dalam beberapa kesempatan mereka berkunjung ke Indonesia untuk memberikan seminar di lembaga Al-Risalah.

Struktur Organisasi secara mikro yaitu Al-Risalah memiliki 1 orang pimpinan sekaligus pendiri Al-Risalah, 6 pengajar, 3 orang staf, 1 orang supervisor dan 100 lebih siswa dan siswi.

\section{Planning}

Jika dilihat dari segi perencanaan, lembaga Al-Risalah menyediakan beberapa program mulai dari program training pelatihan pembelajaran bahasa Arab, kuliah umum dan seminar, bahasa Arab profesi, program bahasa Arab intensif. Sedangkan dari segi metode, AL-Risalah menyelenggarakan program secara klasikal dengan menerapkan kombinasi presentasi, diskusi dan praktik berbicara percakapan bahasa Arab.

Sebagaimana menurut Ali "Metode yang digunakan adalah practice sebab bahasa Arab bukan lagi menjadi bahasa asing di Indonesia, bahasa Arab digunakan dalam AlQur'an dan shalat." Lebih lanjut Ali menyebutkan bahwa "manajemen yang kita terapkan di Al-Risalah adalah manajemen Islami dimana semua dosen disini disarankan untuk menanyakan kendala bahasa para siswa Al-Risalah."

Dalam perencanaan pembelajaran, Al-Risalah menggunakan kitab al-Ārabiyyatu Bayna Yadayk. Penggunaan kitab ini dirancang untuk menunjang keterampilan berbahasa siswa dalam memahami 4 keterampilan yaitu: mendengar, membaca, menulis dan berbicara. Penulis mengamati bahwa rencana pembelajaran yang ada di Al-Risalah sangat ideal sesuai dengan keadaan. Dengan perencanaan ini dapat mengcover siswa yang berasal dari latar belakang yang berbeda-beda. Mulai dari IRT, dosen, siswa, dan mahasiwa.

\section{Organizing}

Dalam hal struktur organisasi, lembaga Al-Risalah memiliki seorang pimpinan, dewan penasehat, dosen, bendahara, staf dan para siswa yang tidak terbatas dalam masalah waktu. Latar belakang para dosen di Al-Risalah memiliki jenjang pendidikan Strata 3. Hal ini sesuai dengan apa yang disampaikan oleh Ali (2019) bahwa "semua dosen adalah doktor yang ahli dalam bahasa Arab". Ida Nurjannah (2019) menyebutkan 
“Al-Risalah melakukan pelaporan pajak perbulan dan sangat menaati aturan pemerintah. Al-Risalah telah memiliki izin dan mendapatkan sertifikat izin penyelenggaraan dari pemerintah setempat."

Berdasarkan pengamatan penulis, seorang bendahara merangkap sebagai penerima tamu. Sebagaimana pernyataan Endang Utari (2019) bahwa saya melayani siswa dan siswi yang ingin membayar biaya kursus biasanya dilakukan pada jam istirahat hal ini agar tidak mengganggu konsentrasi siswa pada saat pembelajaran, saya sebagai bendahara juga merangkap sebagai penerima tamu tidak terpaku pada sistem kerja karena disini kita bekerja dengan sistem kekeluargaan."

\section{Actuating}

Pelaksanaan pembelajaran lembaga Al-Risalah sangat berpaku kepada pimpinan AlRisalah dengan didukung oleh para dosen dan staf administrasi. pada pelaksanaannya, pembelajaran bahasa Arab didominasi oleh kebijakan-kebijakan dari pimpinan AlRisalah. Hal ini tidak mengurangi rasa kesolidan tim dalam bekerja sebab Al-Risalah mengutamakan sistem kekeluargaan. Utari (2019) mengungkapkan bahwa dalam hal pertemuan dan pembahasan biasanya tidak terjadwal akan tetapi bersifat situasional, inisiatif dan kerjasama.

\section{Controlling}

Pengevaluasian pembelajaran dilakukan setiap akhir pembelajaran pada setiap buku. Pengevaluasian juga dilakukan pada setiap akhir level. Berdasarkan kitab yang digunakan dibagi menjadi 8 level. Pengevaluasian ini dilaporkan oleh dosen dan ketua lembaga Al-Risalah kepada pimpinan. Bagi siswa yang sudah lulus dan kehadirannya mencukupi maka diperbolehkan ke level berikutnya. Sedangkan pengevaluasian pada kinerja staf dilakukan setiap saat. Hal ini dilakukan untuk mengetahui apa saja yang menjadi hambatan dalam bekerja.

\section{KESIMPULAN}

Manajemen Al-Risalah yaitu dari aspek planning, organizing, actuating dan controlling dapat disimpulkan sebagai berikut: Dalam perencanaan sudah dilaksanakan dengan baik, sistematis dan memiliki pembagian beberapa kelas berdasarkan levelnya. Namun dari aspek pembelajaran terkadang siswa yang sudah belajar di suatu level harus mengulang ke level yang sama sebab tidak adanya siswa atau kurangnya siswa yang 
berada di level selanjutnya. Hal ini dapat mengasah kembali kemampuan siswa dengan mengulang-mengulang level tetapi di satu sisi siswa tersebut membutuhkan waktu yang cukup lama untuk menyelesaikan program 8 level tersebut.

Dalam pengaturan pelaksanaan fungsi, peran dan tugas yang dilakukan oleh staf masih belum terlaksana dengan baik. Hal ini dikarenakan masih adanya staf yang merangkap tugas. Dari aspek pelayanan cukup baik sebab Al-Risalah mengedepankan sistem kekeluargaan. Secara pelaksanaan (actuating) sudah berjalan sebagaimana yang diharapkan yaitu siswa mampu menguasai 4 keterampilan di lengkapi dengan fasilitas yang disediakan oleh Al-Risalah guna mendukung konsentrasi siswa. Controlling dilaksanakan secara rutin dimulai dari controlling perhari, perpekan, perminggu.

\section{DAFTAR PUSTAKA}

H, A. W. (2020). Human Resources Development Analysis Based on Total Quality Management at Daarul Qur 'an Elementary School Semarang. International Conference on Science and Education and Technology, 443(Iset 2019), 336-340.

Iskandar, I., Ali, B., \& Mahmuddin, M. (2017). Manajemen Dakwah Ma‘Had Al-Sunnah Kabupaten Sidrap. Jurnal Diskursus Islam, 5(1), 43-66. https://doi.org/10.24252/jdi.v5i1.9640

Kholili, A. N., \& Fajaruddin, S. (2020). Manajemen strategik peningkatan mutu lembaga pendidikan Muhammadiyah di Kabupaten Gunungkidul. Jurnal Akuntabilitas Manajemen Pendidikan, 8(1), 53-69.

Mohammad Muchlis, S. (2008). Pendidikan Islam Klasik: Telaah Sosio-Historis Pengembangan Kurikulum Pendidikan Islam Masa Awal Sampai Masa Pertengahan. Tadris, 3(2), 18.

Msallam, A. A., Al, A. A., Naser, S. S. A., \& Shobaki, M. J. Al. (2020). The Reality of Achieving the Requirements of Total Quality Management in University Colleges. International Journal of Academic Management Science Research, 4(8), 67-90.

Sewang, A., \& Halik, A. (2020). Learning Management Model of Islamic Education based on Problem: A Case Study of the Tarbiyah and Adab Department of IAIN Parepare. Talent Development \& ..., 12(1), 2731-2747. 
http://repository.stainparepare.ac.id/1336/

Taufiqurrochman, R., Muslimin, I., Rofiki, I., \& ABAH, J. A. (2020). Students' Perceptions on Learning Management Systems of Arabic Learning through Blended Learning Model. Jurnal Al-Bayan: Jurnal Jurusan Pendidikan Bahasa Arab, 12(1), 22-36. https://doi.org/10.24042/albayan.v12i1.5276

Widyastri, S. (2018). Peran lembaga Tahfizh dan Qiraat (LTQQ) dalam Meningkatkan Kualitas Bacaan Al-Qur'an di Institut Ilmu Al-Qur'an (IIQ) Jakarta (Nomor December) [PTIQ Jakarta]. https://doi.org/10.13140/RG.2.2.34058.62404

Widyastri, S., \& Iskandar, I. (2020). Analisis Manajemen Lembaga Tahfidzh dalam Meningkatkan Kualitas Bacaan Al-Qur'an Mahasiswi IIQ Jakarta. Darul Ilmi Jurnal Ilmu Kependidikan dan keislaman, 08(01), 17-32.

Wijaya, C. (2020). Strategi Manajemen Kepala Madrasah dalam Mengembangkan Sumber Daya Guru di MTS Persiapab Negeri Hadundung Kecamatan Kota Pinang Kabupaten Labuhan Batu Selatan. Edu Riligia, 4(1), 91-102.

Wawancara

Ali Husein Morgan, Pimpinan sekaligus penggagas lembaga Al-Risalah, Jakarta, 08 Desember, 2019.

Endang Utari, bendahara sekaligus staf Administrasi Al-Risalah, Jakarta 16 Desember 2019.

Ida Nurjannah, kepala lembaga, Jakarta 24 Desember 2019. 